\title{
The effect of monetary policy of Central Bank on activities of Tehran Stock Exchange
}

\author{
Hossein Vazifehdust ${ }^{\mathrm{a}}$, Karim Ghalmegh ${ }^{\mathrm{b}^{*}}$ and Kianoush Nazari Ameleh
}

${ }^{a}$ Assist Prof, Department of Business Management, Science and Research Branch, Islamic Azad University, Tehran, Iran

${ }^{b}$ Department of Accounting, Gonbad Kavus branch, Islamic Azad University, Golestan, Iran

${ }^{c}$ Department of Business Management, Science and Research Branch, Islamic Azad University, Tehran, Iran

\section{H R O N I C L E A B S T R A C T}

Article history:

Received May 1, 2013

Received in revised format 10 July 2013

Accepted 12 July 2013

Available online

July 142013

Keywords:

Monetary policy

Consumer goods and services

price index

Exchange rate

Liquidity volume

Share price index and trading

volume

\section{Introduction}

Study of the relationship between macroeconomic variables and the Tehran Stock Exchange allows investors to understand the concept of systematic risk (market risk). In general, the overall risk of an investment is divided into two systematic and nonsystematic components, with nonsystematic risk being the special part of every investment activity, and affected by internal conditions of project concerned, which can be reduced or eliminated by increasing diversity of investments. However, systematic risk is the general part of the risk, which results from general conditions of society, and may not be removed, but investors must try to gain yield in proportion with systematic risk of each

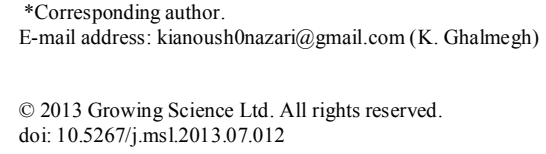


project. In investment, the overall risk is important. However, considering the above mentioned, systematic risk is more important than nonsystematic one.

The aim of this study is to explore the relationship between monetary policy of the central bank and activity of the stock exchange, the reason behind choosing this subject is the importance of understanding environmental condition risk (systematic risk) and, the high volatility of environmental factors in Iran country, especially in last recent years. Similar research was previously conducted, including master's thesis of Javadi (2001), which had a broader subject, compared with present research. In addition, Javadpour (2004) studied the relationship between changes in macroeconomic indices and variations in Tehran Stock Exchange share prices index.

Monetary policy in broad sense of the world and may be defined as any policy related to supply of money. Since the most important institution related to supply of money is the central bank of every country, therefore, monetary policy may be defined as "guidelines, policies, reports and measures of central bank, especially those adopted by the government-appointed head of central bank, which affects aggregate demand, as well as national spending" (Labonte \& Makinen, 2006).

Consumer goods and services price index as a measure of changes in prices of goods and services for household consumption is the most important tool for measuring inflation in the country. Essential and diverse application of this index are in estimation of purchasing value of country's currency, measuring income trend, and real cost of households, adjusting wage and salaries, and adjustment of national accounts at fixed price shows importance and place of the said index in economic studies and planning (Iran Census Bureau, 2011).

Exchange rate is defined as number of unit foreign currency exchangeable for unit, or as number of unit local currency exchangeable for unit foreign currency (McKinnon, 1979). Given behavior of financial institution, natural definitional for liquidity is growth rate of consolidated balance sheet, more precisely, growth rate of reserves, because reserves and other forms of reserves are used as a means to modify balance sheet by financial institutions (Adrian \& Shin, 2008, 2010). Interest rate is a sign, which influence direct flow of funds from supplier or savers towards demanders.

Index generally means indicator. The term index is a quantity representing several homogeneous and is a tool to measure and to compare the phenomena of specific nature and properties, based on which one may study the changes in certain variables during a period of time. It is possible to calculate index for each company, industry group, or category (Tehran Stock Exchange, 2011),

Total_price_index: One of the main indices is TEPIX, which is the abbreviation of the Tehran Stock Exchange, which is calculated according to the following formula (La Spears formula):

[(Current market value $\times$ number of issued shares) (divided by) (share base value $\times$ Number of shares in base year) $] \times 100$

Base year in this calculation is the year 1990. This index indicates that the total market value multiplied, compared to the base year, or the year 2011. For example, 12700 indicates the market value of the base year 1990 has increased by a factor of 127 compared with the base.

In Tehran Stock Exchange, total price index was calculated for the three groups as follows:

1- Total market price index: share price of all companies traded on the stock market are accounted for in calculation of this index. 
2- Price Index of Main Market: only share price of companies traded on main board are accounted in calculation of this index.

3- Price Index of Secondary Market: only share price of companies traded on secondary board are accounted in calculation of this index.

Cash yield index: this calculated as logical difference between price index and cash yield, and indicates cash yield variations of shares. Background of this research is divided into two main categories:

Bullard and Schaling (2002) used a simple macroeconomic technique to study the implications of making inflation, output, and share prices targeted. They showed that policy, which reacts to increase in the share price can be harmful because it can intervene in ability of policy makers to minimize inflation and output fluctuations. They also demonstrated that under certain circumstances, policy of making stock market prices targeted could result in stillness of irrational rational expectations. Therefore, this could result in more unexpected fluctuations, if assets prices were not overlooked. They concluded that making stock market targeted would reduce effectiveness of monetary policies, and can lead to actual damage, while such damages were impossible if the focus was on net targeting. Therefore, monetary policy must overlook stock market.

Goodfriend (2002) found similar results. He also stated that direction and size of illicit relations between trend of asset prices and real short-term interest rates was not sustainable. Thus, in principle, it is actually very difficult to response to the share price. Finally, Filardo (2001) described the role of monetary policy in an economy with asset bubbles by developing a small-scale macroeconomic model and implementing different simulations of different. He found that if there is no certainty about the role of asset prices in the outlet and inflation, monetary policy should react to asset prices. If monetary authority were uncertain enough about macroeconomic results concerning share prices, it would be better for monetary policy to remain indifferent.

\section{Research Method}

This study examines the relationship between monetary policy variables, which are part of the macro and uncontrollable factors affecting the stock exchange activity and activity of Tehran Stock Exchange. The main hypothesis of this research was to investigate the impact of monetary policy on stock exchange activity. Similar to comparative studies of Turkey, the US and European Union, first we considered variables associated with monetary policy to be four variables of consumer goods and services prices index, exchange rate, liquidity volume and interest rates. However, for the following reasons, we were forced to exclude variable of interest rates: in all models of this research, first, interest variable have a significant relationship with the dependent variable and causes collapse of model.

Secondly, interest rate as a monetary policy tool has been faced with religious constraints and has not been applicable. Third, interest rate has not experienced significant change in Iran in recent years, so that it could not play role as a policy making leverage. Therefore, the said variable was excluded from independent variable of this research.

Finally, it seems that the three above said variables are good variables to explain monetary policy in Iran. To measure the activity of a stock exchange, variables of share price index, trading volume, and cash yield index are used. It seems that these three variables are good variables to describe the stock market activities in Iran. After collecting data on the dependent and independent variables, to examine durability of time series, we have used unit root test with the aid of EVIEWS software. After 
that, the test of hypotheses related to three sub-hypotheses has been conducted using EVIEWS software. Then, all models were examined in terms of autocorrelation and heteroscedasticity of variance (aided by White test).

In terms of objective, this research an applied one, because it seeks to study their efficiency based on the Tehran Stock Exchange within the framework of the neo-classicists' macroeconomic monetary policies theory. However, in terms of method, it is a descriptive research, because it describes the current status of the effects of components of expansionary - contractionary policy of central bank on share price in one decade.

The main hypothesis of the research studies the impact of central bank monetary policy on Tehran Stock Exchange activity, which is decomposed into three sub-hypothesis as follows:

Variables related to monetary policy influence on total share price index of Tehran Stock Exchange.

Variables related to monetary policy influence on trading volume at the Tehran Stock Exchange.

Variables related to monetary policy influence on the share index yield of Tehran Stock Exchange.

To test each of these hypotheses, we look for a linear relationship - econometric patter - between the dependent variable and the independent variables, which are the very monetary policy variables. Our models in this research are:

The first sub-hypothesis model: $Y_{1}=a+B_{1} X_{1}+B_{2} X_{2}+B_{3} X_{3}+B_{4} X_{4}$ The second sub-hypothesis model: $Y_{2}=a+B_{1} X_{1}+B_{2} X_{2}+B_{3} X_{3}+B 4 X 4$

The third sub-hypothesis model: $Y_{3}=a+B_{1} X_{1}+B_{2} X_{2}+B_{3} X_{3}+B_{4} X_{4}$

The fourth sub-hypothesis model: $Y_{4}=a+B_{1} X_{1}+B_{2} X_{2}+B_{3} X_{3}+B_{4} X_{4}$

Independent variables of this research are:

$X_{1}=$ price index of consumer goods and services in urban areas of Iran, $X_{2}=$ exchange rate, $X_{3}=$ liquidity $X_{4}=$ inflation.

The dependent variable of this research are:

$Y_{1}=$ Share price index, $Y_{2}=$ quarterly trading volume (seasonal) of Tehran Stock Exchange and $Y_{3}=$ cash yields index

Statistical population in this research included all companies listed in Tehran Stock Exchange and stock exchange indices as representatives of the entire stock exchange and variables associated with monetary policies of central bank including time series seasonally generated by central bank over the period 1995-2002.

In this research, first, data related to above said variables for one decade were collected from libraries, and website of stock exchange, library and website of central bank, library and website of Iran Census Bureau, etc. Then, trend of time series related to dependent and independent variables was studied and their average over studied years was calculated. Then, to investigate durability of time series, unit root test was used with the aid of EVIEWS software. To do so, t test statistic is calculated using software, and its critical limit is extracted from table. If absolute value of calculated statistic is greater than critical limit from table, assumption of durability of time series is confirmed, and otherwise, the assumption is rejected. Fortunately, having conducted the test, time series related to all variables were durable at intended level of significance. 
Before testing hypotheses, an important point to note is that the variable $X_{4}$ (interest rates) for the reasons given in this section was excluded from the independent variables of the study. Then test of hypotheses related to three sub-hypotheses was conducted using EVIEWS software, which fortunately, given high F statistic in all models, relation between dependent and independent variable in these model had a high level of significance. Then, all models were studied in terms of autocorrelation and heteroscedasticity of variance (aided by White test), and it was concluded that there was no correlation in all these models, and also in model related to sub-hypothesis 1 and 2, independent variables or their square had no significant relation with root-mean-square error. Therefore, models 1 and 2 did not have heteroscedasticity of variance. However, in model related to sub-hypothesis 3 , variable $X_{13}$ had a significant relation with error root mean square. Therefore, this model also has heteroscedasticity of variance. To solve this problem, we implemented the model using weighted regression and by allocating weight of $\left(\mathrm{X}^{.5}\right)^{-1}$. White test was repeated and it was observed that none of independent variables or their square is significantly related to root mean square. Therefore, the problem of heteroscedasticity of variance is also solved. Finally, considering outputs of software, models related to this research were written as follows:

The regression equation of the first sub-hypothesis:

$\mathrm{Y}_{1}=259.69+46.6 \mathrm{X}_{14}-0.19 \mathrm{X}_{24}-0.05 \mathrm{X}_{34}$

Durbin-Watson stat $=1.68$

$\mathrm{R}^{2}=0.84$

Constant value of 259.69 means that if all the independent variables included in the model are equal zero, then the total share price index shall be equal to 259.69 units. Also, the price index of consumer goods and services for a four-year period, that is, with one year of delay $\left(X_{14}\right)$, has the highest coefficient, the positive sign of its respective coefficient indicates positive strong relation of it with total share price index, which may be explained by effect of inflation on overall stock exchange activities. This is because as overall price levels increase, and consequently, profit of stock market listed companies and their share price increases, finally the total share price index increases.

The next variable in the model discussed above is the exchange rate in the open market during a fouryear period with one-year delay $\left(\mathrm{X}_{24}\right)$. Negative sign of this coefficient, which indicates its negative relationship with total index may be explained by two reasons. First, as exchange rate changes, and climbs, many investors of stock exchange transfer their capital partly or wholly from stock market to foreign exchange market, which results in increase in supply of share compared with demanded share, resulting in decline in share price and following total index. The second reason lies in direct or indirect dependence of listed company on foreign raw materials.

The last variable in the model with a negative sign is liquidity. The main reason confirming this relation is that most part of liquidity consists of people deposits held by banks, including sight, interest free or investment deposits. Increase in level of such deposits indicates that capital has exited capital market, or at least, that enough new investments are not made in stock exchange.

The regression equation of the second sub-hypothesis:

$Y_{2}=789586.4+0.004 X_{14}-0.15 X_{24}-0.25 X_{34}$

Durbin-Watson stat $=1.54$

$R^{2}=0.80$

Constant 789586.4 means that if all the independent variables included in the model are equal to zero, the trading volume is still 789586.4 units, which shows the effect of other variables than above said variables on trading volume. Also, liquidity with four-year period, that is one year delay $\left(X_{34}\right)$ has the highest coefficient, the positive sign of which indicates positive strong relation between this variable 
and trading volume, which can be explained by the fact that when liquidity increases in society, currency held by people increases, and consequently trading volume increases in all markets, including stock market.

The next variable in the model discussed above is the exchange rate in the open market during the four-year period, which is one-year delay $\left(X_{24}\right)$. Negative sign of coefficient of this variable indicates negative relation between this variable and total index, which can be explained by the fact that when exchange rate changes and climbs, many investors of stock exchange transfer their capital from stock exchange to foreign currency market partly or wholly, resulting in reduced trading volume of shares.

The last variable with a positive sign in the model is the price index of consumer goods and services during the four-year period, that is, one-year delay $\left(X_{14}\right)$. However, coefficient of this variable in above model is trivial, indicating weak relation between price index of consumer goods and services and trading volume.

The regression equation of the third sub-hypothesis:

$Y_{3}=60.14+0.006 X_{14}-0.13 X_{22}+0.34 X_{34}$

Durbin-watson stat $=1.80$

$\mathrm{R}^{2}=0.79$

Constant value of 60.14 means that if all the independent variables included in the model are equal to zero, then cash yield index is still 60.14 units, which shows effect of other variables than above variables on cash yield index. In addition, liquidity with four years period, that is, one-year delay $\left(X_{34}\right)$ as the greatest coefficient, and the positive sign of it indicates positive strong relation of this variable with cash yield index. This can be explained by the fact that when liquidity increases in society, currency held by companies increases, and as a result, dividend is paid to shareholders as soon as possible, resulting in increased cash yield index.

The next variable in the model discussed above is the exchange rate in the open market, with two periods, that is, 6-month delay $\left(X_{22}\right)$. The negative sign of coefficient of this variable indicates negative relation of this variable with total index, which can be explained by the fact that when exchange rate changes, and climbs, many investors of stock exchange transfer their capital from stock exchange to foreign exchange market partly or wholly, resulting in reduced trading volume and consequently decreased cash yield.

The last variable with positive sign appearing in above model is the price index of consumer goods and services, with three periods, that is, nine-month delay $\left(\mathrm{X}_{13}\right)$. However, coefficient of this variable is trivial in above model, suggesting weak relation between price index of consumer goods and services and cash yield index of stock market, but their relation is significant.

\section{Findings, discussion and conclusion}

Based on the results of our survey we can conclude that there is a strong relation between monetary policy variables and trading volume but the relationship between monetary policy variables and cash yield index was not strong. However, considering strong relation between variables and cash yield index and trading volume and relatively strong relation between variables and cash yield index, the main hypothesis, that is, effect of monetary policies on activities of stock market was also accepted.

Previous research demonstrated the major impact of macroeconomic variables on stock activity, and type of the relationship between variables of inflation, industrial production index, and exchange rate and oil price with share price index has been determined. In this study, the relationship between 
monetary policy variables, consumer goods and services price index, exchange rate, liquidity and interest rates, and stock exchange activity indices, share price index, trading volume and cash yield index, was investigated. Fortunately, the results of this study were highly consistent with the results of other studies in this area. According to Javadpour (2004), share price index is directly associated with industrial productions index, and exchange rate, and inversely associated with oil prices. In addition, oil price is inversely associated with all studied variables. In this research, by study of trend of change, and considering view of economic indicators, we have tried to identify precedent, coincident and delay indicators.

Given the independent variables with fixed prices, it can be seen from diagram that the variable $X_{3}$ (liquidity) is the precedent indicator in both boom and stagnation periods, compared with share price index, and the amount of precedence of $X_{3}$ is 5 time periods, that is one year and three months.

$\mathrm{X}_{1}$ (Consumer goods and services in urban areas of Tehran), the precedent indicator is relative to share price index at fixed price, and time interval of $X_{1}$ and share price index at fixed price is 4 periods, that is one year. In other words, as customer goods and services price index increases, stock exchange reaches the lowest share price after one year, and as customer goods and services price index increase, stock exchange reaches the highest share price after one year.

$\mathrm{X}_{2}$ (exchange rate) in boom and stagnation, with two and a half period, that is, 7.5 months, is the precedent indicators relative to share price index at the fixed price. Given the coefficient of variable $\mathrm{X}_{1}$ in most models, activity of Tehran Stock Exchange is directly associated with and highly correlated with inflation. The reason is that under inflation conditions, value of substitution of corporate assets increases, and increased current value of assets results in increased share prices, and consequently increased share price. Also, increased share price index results in boot of stock exchange, and trading volume and cash yield index.

Given the coefficient of variable $\mathrm{X}_{2}$ in most models, activity of Tehran Stock Exchange is inversely related with exchange rate. The reason is as exchange rate changes, and climbs; many investors of stock exchange transfer their capital partly or wholly from stock market to foreign exchange market, which, as seen in most studied models, results in decline in share price and cash yield index.

Given the coefficient of variable $\mathrm{X}_{3}$ in most models, activity of Tehran Stock Exchange is directly associated with and highly correlated with liquidity. The reason is that when liquidity increases in society, currency held by people increases in most markets including stock market, and consequently, as seen in most studied models, share price index and cash yield index increases.

Given high deciding coefficient in most models, it can be said that due to low presence of private sector, and thorough presence of public sector in economy of Iran, effect of major factors, which are mostly controlled by government is very high in success or failure of company, and increase or decrease of its profitability. Effect of uncontrollable variables of management of institutions and companies is much more and more critical than controllable variables of management. In addition, in Iran capital markets, due to monopoly of public sector, including banks, insurance companies, and government, semi-government investment companies, trend of variation of share price, and share price index are mostly related to major economic and political factors, etc.

\section{Limitations and future research:}

- The first problem facing us was to specify coincidence indicators. 
- Although the precedence or delay of indicators is relative, but we should finally consider a basis for economic boost, and with little indulgence, we finally chose share price index of Tehran Stock Exchange as coincidence indicator, comparing the rest against it.

- Given this research was conducted using linear models, it is suggested that the same is conducted using non-linear models, which will certainly give better results.

\section{References}

Adrian, T., \& Shin, H. S. (2008a). Liquidity, monetary policy, and financial cycles. Current issues in economics and finance, 14(1).

Adrian, T., \& Shin, H. S. (2008b). Financial intermediary leverage and value-at-risk (No. 338). Staff Report, Federal Reserve Bank of New York.

Adrian, T., \& Shin, H. S. (2010). Liquidity and leverage. Journal of financial intermediation, 19(3), 418-437.

Bullard, J. B., \& Schaling, E. (2002). Why the Fed should ignore the stock market. Review-Federal Reserve Bank of Saint Louis, 84(2), 35-42.

Filardo, A. (2001). Should monetary policy respond to asset price bubbles? Some experimental results. Some Experimental Results (July 2001). FRB of Kansas City Working Paper, (01-04).

Goodfriend, M. (2004). Monetary policy in the new neoclassical synthesis: a primer. FRB Richmond Economic Quarterly, 90(3), 21-45.

Meltzer, A. H. (2000). Monetary policy in the new global economy: the case of Japan. Cato J., 20, 69.

Javadpour, M. (2004). The relationship between changes in macroeconomic indices and variations in Tehran Stock Exchange share prices index. Master Thesis, Shahid Beheshti University, Tehran, Iran.

Javadi, J. (2001). Effect of macroeconomic variables on share price index of Tehran Stock Exchange during the period 1980-1993. Master Thesis, University of Shahid Beheshti, Iran.

Krugman, P. R. (2008). International Economics: Theory And Policy, 8/E. Pearson Education India.

Labonte, M., \& Makinen, G. E. (2008, December). Monetary Policy and the Federal Reserve: Current Policy and Conditions. Congressional Research Service, Library of Congress.

McKinnon, R. I. (1979). Money in International Exchange: The Convertible Currency System: The Convertible Currency System. Oxford University Press, USA. 